\section{Aspectos éticos dos testes preditivos em doenças de manifestação tardia}

\section{Ethical aspects of predictive tests for late- onset disorders}

Alvaro Angelo Salles 1

\footnotetext{
1 Faculdade de Ciências Médicas de Minas Gerais. Alameda Ezequiel Dias, 275. Belo Horizonte, MG, Brail. CEP: 30.130-110. E-mail: alvaroangelo5@yahoo.com
}

\begin{abstract}
The article discusses some of the bioethical implications of the application of predictive tests for lateonset disorders. Questions are raised which may help guide decision-making regarding the use of predictive tests along with issues connected with the bioethical principles of respect for autonomy, justice, beneficence and harm. It is observed that there is a concern to preserve a life-ethic that parallels technical and scientific advances in the field of genetics. It is concluded that it is always beneficial to engage in ethical reflection regarding the early diagnosis of late-onset genetic disorders.
\end{abstract}

Key words Bioethics, Genetics, Genetic testing, Genetic predisposition to disease, Anticipation genetic

\section{Resumo}

Discutem-se aqui, da perspectiva bioética, algumas das implicações da aplicação de testes preditivos em doenças de manifestação tardia. São sugeridos questionamentos que podem ajudar a nortear a decisão sobre o uso dos testes preditivos e é feito um paralelo entre esses questionamentos e os princípios bioéticos de respeito à autonomia, justiça, beneficência e não maleficência. Observa-se, como resultado, a existência de uma preocupação com o resguardo de uma ética de vida em paralelo aos avanços tecnocientíficos no campo da Genética. Conclui-se pelo benefício de uma constante reflexão ética sobre a questão do diagnóstico prévio de doenças genéticas de início tardio.

Palavras-chave Bioética, Genética, Testes genéticos, Predisposição genética para doença, Antecipação genética 


\section{Introdução}

\section{O surgimento do diagnóstico preditivo}

Com o desenvolvimento do Projeto Genoma Humano, tornou-se possível verificar, pela análise de genes, que patologias um indivíduo tem potencialmente e cuja manifestação ocorrerá em algum momento do futuro, ou, ainda, quais são suas predisposições genéticas para manifestar determinadas doenças, também no futuro. Dessa forma, a medicina teve o seu campo de ação ampliado com o aparecimento dos exames para diagnóstico de doenças de manifestação tardia.

Iniciados na década de 80 , época em que se desenvolviam pesquisas na área da genética, os diagnósticos pré-sintomáticos dariam apoio ao aspecto preventivo das ações médicas, até então mais voltadas para o tratamento de doentes. Os exames agora passariam a incluir o indivíduo são (até mesmo em sua fase pré-natal) e objetivariam prever, evitar ou amenizar seus males ainda não manifestados. Estabelecia-se, assim, uma medicina preditiva, que, com base na investigação tecnocientífica, não só possibilitaria ao indivíduo ter acesso à sua história de saúde futura, como, ainda, facilitaria as ações de uma medicina preventiva, já que o indivíduo, apoiado em informações genéticas, teria a oportunidade de planejar sua vida de acordo com seu potencial de saúde e doença e, principalmente, de tomar providências para o tratamento e eventual cura de uma doença prevista. 1

Cada vez mais, as doenças genéticas podem ser diagnosticadas ou confirmadas pelo diagnóstico genético, o que significa a não necessidade de outros exames menos informativos ou, muitas vezes, invasivos. De uma perspectiva imediata e simplista, portanto, o aspecto utilitário do uso de testes preditivos parece indiscutível. Entretanto, desde o surgimento do primeiro exame para diagnóstico présintomático de doenças genéticas que se manifestariam no futuro, verificou-se que havia inúmeras implicações em seu uso - mormente as que envolviam aspectos éticos e morais. Estava inaugurada uma série de longos debates sobre o assunto, debates esses que têm achado esclarecimento e orientação nos princípios bioéticos.

\section{O surgimento dos questionamentos}

São inegáveis as contribuições da genética para a compreensão de como os genes funcionam e por que as alterações neles apontadas geram doenças. O conhecimento das doenças que o indivíduo manifes- tará - ou que tem chances de manifestar tardiamente - possibilita, no mínimo, as pesquisas sobre elas e o progresso em direção à cura daquelas patologias; dá oportunidade ao tratamento preventivo; e, ainda, fornece respostas que, em outras circunstâncias, só viriam após inúmeros exames, muitas vezes invasivos ou menos acurados. Além disso, como acontece no caso de patologias cujo tratamento é conhecido, a identificação da doença ainda na fase pré-sintomática, pelo exame dos genes, torna-se de extrema utilidade por possibilitar que o avanço do mal seja retardado ou mesmo evitado. Na hipótese de doenças graves cujo tratamento seja ainda desconhecido, a identificação de mutações genéticas em indivíduos assintomáticos cria, a partir do diagnóstico pré-natal, a opção de se evitar o nascimento de novos indivíduos com as mesmas doenças.

Entretanto, essa contribuição indiscutível para o diagnóstico prévio dos males da humanidade motiva, desde sua introdução, múltiplos questionamentos, em razão das consequências - individuais, familiares, sociais, psicológicas e éticas, entre outras de sua aplicação.

O marco inicial desses questionamentos e da generalização dos debates em relação ao diagnóstico prévio é considerado a apresentação, em 1983, do teste que, por meio da análise do ácido desoxiribonucleico (DNA) humano, revelaria se um indivíduo (até então assintomático) possuía ou não o gene causador da doença de Huntington, ${ }^{2}$ patologia que geralmente se manifesta só após os 50 anos de idade. Tornava-se possível, então, em qualquer fase da vida e muito antes do aparecimento de sintomas, determinar, no âmbito de uma família em que eram conhecidos casos da doença de Huntington, quais de seus membros haviam herdado o gene por ela responsável.

Esse primeiro caso de diagnóstico présintomático de doença genética com manifestação tardia imediatamente motivou questionamentos 2 sobre os direitos do cidadão com relação a seus empregadores e suas seguradoras de saúde; sobre constrangimentos do indivíduo perante familiares, amigos e sociedade; sobre as implicações psicológicas do conhecimento antecipado de uma doença séria em seu futuro; sobre as vantagens e as desvantagens envolvidas no processo; sobre a confiabilidade do diagnóstico; sobre o direito de se testar indivíduos sãos; e sobre muitos outros aspectos ligados a essa nova conquista tecnocientífica.

Às questões levantadas pelo caso Huntington, muitas outras se acrescentariam como resultado de diferentes variáveis que cada caso apresentaria, pois, com a expansão das pesquisas sobre DNA, desen- 
volveram-se testes para detectar genes relacionados também a doenças comuns na idade adulta. Verificase, hoje, que não há limite para o número de questionamentos já feitos ou a serem apresentados a cada discussão sobre a aplicação dos testes preditivos, não sendo possível uma sistematização mais acurada das interrogações tal o número de variáveis contidas em cada questão.

\section{Os questionamentos básicos sob a perspectiva} da bioética

A pergunta mais abrangente sobre a aplicação de testes preditivos é, provavelmente "os testes preditivos devem ou não ser feitos?" para a qual acreditamos só existir uma resposta aplicável a todos os casos: depende. Isso porque não há dois casos iguais e não há variáveis idênticas em nenhum deles, o que não impossibilita a discussão, mas estabelece " $a$ priori" que, em relação a diagnósticos preditivos, qualquer decisão geral imposta pode estar desrespeitando a individualidade da pessoa envolvida, que é única.

$\mathrm{O}$ respeito à individualidade, do nosso ponto de vista, seria traduzido nessa área da medicina por atitudes como:

- cuidados dispensados ao paciente na fase da informação sobre os aspectos do teste e da possível doença;

- pesquisa ou entrevista cuidadosa sobre as condições psicológicas, físicas, sociais, familiares e, mesmo, financeiras do paciente (entre outras), condições que, muitas vezes, determinarão a boa ou má acolhida do resultado dos testes;

- acompanhamento do paciente durante e após os testes.

Considerando a questão da individualidade à luz de princípios bioéticos, acreditamos que esses três aspectos mencionados devam ser sempre observados quando se procura decidir sobre a aplicação ou não de testes preditivos.

Outra pergunta que ajuda a nortear uma reflexão sobre testes preditivos é: "na possibilidade de realização de um diagnóstico preditivo, quem deve ser a ele submetido?" Essa é uma questão diretamente ligada ao princípio bioético do respeito à autonomia e relacionada, ainda, ao aspecto dos cuidados dispensados ao paciente, antes mencionado.

Como o teste pode ser feito não só no adulto capaz de responder por seus atos, mas também nos que não têm conhecimento ou condições para decidir (como crianças, adolescentes, seres em fase pré-natal e deficientes mentais, por exemplo), pode-se questionar se a autonomia não estaria sendo desres- peitada quando não houvesse concordância expressa em relação ao exame. Coutinho (2006: 52) 3 ressalta que a autonomia "pressupõe que a pessoa é livre para fazer suas escolhas pessoais desde que suficientemente esclarecida. Deve ter liberdade de pensamento e estar livre de coações para escolher entre alternativas apresentadas. Se não há chances de escolha ou alternativa apresentada, não há exercício da autonomia." Pelo aprendizado resultante dessa definição, fica claro que os testes preditivos devem ser aplicados, primordialmente, em adultos que procurem espontaneamente esse tratamento.

Sabe-se que a capacidade de tomar decisões é elemento basilar na aplicação do princípio da autonomia, e que, por outro lado, depende em muito da posse de informações. Pressupõe-se, então, que, se um adulto decidiu, livremente, procurar por um diagnóstico preditivo, ele tem (ou vai querer receber) informações sobre o assunto. A questão é: "o indivíduo vai receber informações suficientes para ajudá-lo em suas opções sobre testes preditivos?" Tome-se, como exemplo o caso do câncer de mama. Em famílias nas quais existe maior frequência dessa patologia, é compreensível verificar se a mulher herdou o gene responsável por esse mal. Por outro lado, se ela pertence a outro tipo de família que não manifesta a doença, merece ser discutida a questão do chamado life time risk, a previsão de risco que a mulher tem de desenvolver câncer durante a vida, e que é de cerca de $10 \%$ nesse caso. 4 Essa mulher do segundo tipo de família mencionado seria informada de que, se fizer os testes e seus genes não demonstrarem mutações, seu risco de desenvolver câncer durante a vida continuará a ser de $10 \%$ ?

Antes ainda de dar informações ao interessado, é conveniente que o médico (ou o responsável por essa parte do processo, como um conselheiro) verifique qual o motivo que levou o indivíduo a procurar voluntariamente esse tipo de diagnóstico, informação que revelaria bastante sobre as suas condições de assumir os resultados. Afinal, que reações podem ser esperadas de um indivíduo cujo teste deu resultado positivo para uma doença ainda incurável, a se manifestar em seu futuro?

Há de se considerar também o envolvimento de outras pessoas (os membros da família, por exemplo), caso os testes revelem patologias mais importantes. Até que ponto a autonomia do indivíduo pode significar a desconsideração de outras opiniões? Em que profundidade a predição de sua história de saúde e doenças influencia a vida do indivíduo, de sua família e da sociedade à qual ele pertence?

Crucial, ainda, permanece a questão daqueles 
que carecem de condições para exercer sua autonomia, aqueles indivíduos que nunca decidirão por si mesmo (os portadores de alguns tipos de doenças incapacitantes ou deficiências mentais severas, por exemplo), caso em que só será possível agir por meio da autorização expressa ${ }^{5}$ dos que por eles se responsabilizam. Igualmente incapazes de exercer sua autonomia, seriam as crianças. Se a aplicação dos testes preditivos deve privilegiar os adultos, conforme sugerido anteriormente, não deve ser testada a criança de uma família na qual alguma doença tem-se manifestado com frequência? Dentro da presente reflexão, parece-nos aconselhável não fazê-lo se a criança não apresenta sintomas e se não há tratamento conhecido para a doença, dando-lhe, dessa forma, tempo de crescer e decidir por si própria.

Há, também, o caso de doenças cujas possibilidades de cura são maiores quanto mais cedo elas forem detectadas, o que significaria vantagem num diagnóstico feito na fase pré-natal ou da infância. $\mathrm{O}$ dilema traz outra questão para reflexão: "que tipos de doença justificariam a aplicação do teste?”, caso em que estão envolvidos, com frequência, os princípios bioéticos da beneficência, da não maleficência, da proteção e do cuidado.

Até o momento, três tipos de diagnóstico podem ser obtidos por meio dos testes preditivos, segundo a Associação Médica Brasileira e o Conselho Federal de Medicina, citados por Jatene et al.,6 e são os relativos a doenças em que apenas a predisposição aumentada pode ser detectada, as doenças para as quais existem tratamento ou medidas preventivas e, finalmente, as doenças de início tardio para as quais não existe tratamento.

\section{Predisposição genética}

Nesta hipótese, o que se detecta com a realização do exame dos genes são doenças que o indivíduo não tem, mas para as quais revela predisposição (risco aumentado). Trata-se de doenças potencialmente tratáveis, como alguns tipos de câncer, alzheimer, hipertensão ou diabete. O desenvolvimento tardio da doença não é garantido, pois se sujeita a variáveis como fatores psicológicos, físicos, sociais e ambientais. Aceita-se que o diagnóstico, neste caso, possa ser muito importante para futuros tratamentos.

Considerando casos em geral, acreditamos que, se o indivíduo procura saber voluntariamente (exercício da autonomia) de sua predisposição para determinada doença (que ele teme ou que presenciou com frequência na família, por exemplo), o diagnóstico prévio ser-lhe-á vantajoso, pois significa a possibilidade de um tratamento que pode evitar a doença ou reduzir seu avanço ou seus efeitos (beneficência). Naturalmente, é recomendável que tal decisão seja precedida de informações sobre o teste e sobre as possibilidades de tratamento da doença, como já mencionado na discussão do primeiro aspecto para reflexão, salientando-se que se trabalha, nesse caso, com probabilidades, fator que deve ser nitidamente exposto ao paciente. Somente sabendo que as variáveis de sua vida podem significar a não manifestação de uma determinada doença, o paciente poderá exercer sua autonomia de decisão sobre a realização ou não dos testes para a detecção daquela doença.

Outra informação que pode resultar de um teste preditivo é a de que o gene defeituoso encontrado é recessivo e que a doença não se manifestará, mas poderá ser transmitida à prole. Um diagnóstico desse tipo pode significar que a pessoa está livre da doença (beneficência), mas não livre de conflitos em relação à constituição de uma prole (não maleficência).

\section{Doenças cujo tratamento é conhecido}

No caso de doenças que podem ser tratadas, há vantagem no seu diagnóstico prévio, antes da manifestação dos sintomas, o que provavelmente aumentará as chances que aquele paciente tem de nunca vir a lidar com a doença. Novamente, é preciso salientar a importância do conhecimento do médico (ou conselheiro) em relação ao paciente e do preparo do paciente e de sua família. Também acreditamos na necessidade de investigação das outras condições de saúde do paciente, pois, na hipótese da descoberta de uma doença genética que possibilite tratamento, pode acontecer que o paciente, debilitado por outras enfermidades, não possa ser tratado do mal detectado no teste preditivo. Também as condições sociais e financeiras devem ser levadas em consideração, para que ao mal previsto não se acrescente a frustração ou a depressão diante da impossibilidade de tratá-lo (viés da não maleficência). São aspectos de compaixão que não podem ser olvidados da perspectiva bioética.

De modo geral, a adoção dos testes preditivos para doenças cujo tratamento é conhecido tem sido bem aceita por todos e, conforme pondera Nunes (1995: 191)7 "os testes genéticos para doenças de manifestação tardia só devem ser oferecidos pelo geneticista quando existir uma razoável probabilidade de prevenção ou de tratamento eficaz." Mas, repita-se, é necessário o estudo individual dos casos.

Doenças cujo tratamento ainda não foi
$\frac{\text { encontrado }}{\text { No caso de doenças ainda consideradas }}$


incuráveis, as decisões situam-se entre as mais complexas. O princípio da não maleficência parece estar comprometido quando se recorda que, na maioria das vezes, as pessoas sofrem ao tomar conhecimento de que são portadoras de um mal sem possibilidade de tratamento. Também sofre a família. Nesses casos, pode o doente encarnar o papel de um "condenado", sem futuro, não vendo sentido no presente a não ser o de esperar pela morte. Saber que tem, potencialmente, uma doença incurável pode representar profundo sofrimento e depressão para o paciente, como a história ilustra em inúmeros casos, principalmente após o aparecimento da Síndrome de Imunodeficiência Adquirida (AIDS). 8

Torna-se questionável, então, o valor da informação em casos como o de um indivíduo que, a partir de um diagnóstico preditivo feito ainda antes de seu nascimento, pode passar a viver à sombra do conhecimento de que suas capacidades física e mental se perderão após seu aniversário de 50 anos porque é portador do gene da doença de Huntington. Provavelmente lhe serão negados planos de saúde e emprego, e podem ser acrescidos a seu sofrimento a discriminação genética e os efeitos da ignorância que leva os outros (mesmo familiares) a se afastarem dele por medo de um hipotético contágio.

Pensando nas doenças cuja cura ainda não foi descoberta, percebe-se a seriedade de diagnósticos na fase pré-natal, quando não pôde haver ainda o exercício da autonomia pela própria pessoa, havendo de se exigir extremo cuidado em sua indicação. Daí a importância da orientação de Nunes, 7 quando diz que é necessário que se determinem quais patologias devem, pela sua gravidade, ser objeto de rastreio no período antenatal.

São recomendações da Associação Médica Brasileira e do Conselho Federal de Medicina ${ }^{6}$ que o paciente, mesmo nos casos em que tenha voluntariamente procurado pelo teste preditivo, passe por uma avaliação psicológica e tenha um acompanhamento de um profissional antes e depois do diagnóstico. Acrescentam, ainda, aqueles órgãos que qualquer informação a respeito do caso é considerada sigilosa. Nota-se, nessas medidas, a preocupação não só de preservar a dignidade, a autonomia e a liberdade do paciente, mas também de evitar sua discriminação. Deve ser levado em conta, ainda, o aspecto de proteção do paciente, considerando-se que, dentre outras incontáveis consequências, uma informação desse teor pode significar pressão sobre o paciente com relação a, por exemplo, heranças e providências sobre bens, ou disputas familiares, tudo isso representando aumento de sofrimento para o doente.

Ainda uma pergunta merece atenção ao se discu- tirem os princípios éticos envolvidos na realização de testes preditivos: "que princípios terão precedência sobre os outros no momento da decisão?" A indagação relaciona-se, em grande parte, ao princípio da justiça, ao princípio da responsabilidade, ao bem coletivo e à alteridade, pois que ajuda a refletir e resolver sobre, principalmente, a priorização do bem de outros em detrimento do bem individual na decisão pré e pós-realização de um teste genético preditivo.

Nunes (1995: 191)7 defende a realização dos testes na fase pré-natal apenas quando houver razoável probabilidade de prevenção ou tratamento eficaz. Entretanto, após observar que o interesse em não proporcionar o conhecimento do diagnóstico preditivo no período fetal do desenvolvimento pode levar à não realização de testes genéticos para doenças de manifestação tardia, pondera: "No entanto, o sentido de responsabilidade social para com as futuras gerações pode orientar as decisões reprodutivas num sentido contrário à vontade original".

Neste ponto, vale retornar à primeira das questões levantadas neste estudo - os testes devem ou não ser feitos? Tem-se aí uma noção de dever dever para consigo, dever para com os outros - e embutida nela, a noção de necessidade e de justiça: ao fazer o teste, o indivíduo estará sendo justo consigo e com a alteridade?

À questão se aplicaria, como exemplo, o caso de pais que decidem pelo diagnóstico pré-natal com o objetivo de evitarem um filho "imperfeito". Estariam zelando pelo bem do outro ou desconsiderando que o conceito de normalidade é relativo e profundamente ligado à cultura e à capacidade de compaixão e de aceitação do próximo? Estariam os casais, ao optarem pelo diagnóstico pré-natal, sendo "justos" ou praticando uma modalidade de eugenia? Ao mesmo tempo, como não se perguntar também se não é dever do indivíduo cuidar de seu patrimônio genético e evitar a transmissão de genes defeituosos a uma prole? Na visão de Buiatti, ${ }^{9}$ os aspectos éticos desempenham um papel importante e, portanto, devem ser levados em conta não apenas quando se trata de decidir a nossa vida, mas também quando se influi na vida dos nossos semelhantes e dos outros habitantes do planeta Terra. Usando de um exemplo concreto, não deve o indivíduo se questionar se haveria justiça em entregar à sociedade filhos que, de acordo com testes preditivos (antes da implantação ou no período pré-natal), estariam fadados a apresentar deficit intelectual?

Outro caso clássico - o da doença de Huntington, já mencionada anteriormente - é questionável 
também quanto ao aspecto da alteridade e, portanto, quanto ao princípio bioético da responsabilidade. Como o indivíduo tem chance de $50 \%$ de transmitir o gene defeituoso aos filhos, a informação do teste preditivo torna-se importante para sua decisão de formar ou não uma prole. Por outro lado, se o adulto não está mais em idade reprodutiva, cessa naturalmente o valor dos testes no aspecto de responsabilidade quanto à transmissão dos genes. Há o caso também de genes defeituosos, porém recessivos, que indicarão estar o indivíduo livre da doença. Conforme já mencionado antes, o teste seria benéfico a ele, mas fica-lhe a decisão sobre a transmissão dos genes e a possível manifestação da doença nos filhos.

Finalmente, a reflexão sob os princípios da justiça e do respeito à alteridade levam a pensar sobre aqueles que se voluntariam para testes, como, por exemplo, os cientistas que testam experimentos em si mesmos, ou o membro de uma família que apresenta casos de doença incurável e que opta por fazer o teste preditivo com o objetivo de fornecer dados aos pesquisadores e, assim, ajudar aos outros e às próximas gerações. Esse ato de doação e despreendimento, quando o bem comum é colocado acima do bem individual, pode revelar, em nossa opinião, o cultivo profundo de um princípio de compaixão universal e justificar, por si só, a pesquisa e a aplicação de testes para diagnóstico preditivo.

\section{O consenso}

As questões até agora discutidas sobre a aplicação dos testes preditivos podem ser ditas fundamentais. Entretanto, os estudos do genoma humano são recentes e, portanto, bastante questionáveis até em relação ao aspecto da confiabilidade. Assim, muitas outras perguntas se enquadrariam não só aos aspectos aqui salientados para reflexão, mas a novos aspectos ligados aos testes preditivos que vão sendo revelados a cada dia, como, por exemplo: no caso de resultados negativos, há garantia de isenção da doença testada? Descoberta a doença incurável, há de se pensar em tratamento paliativo ou se justificar o teste sob a perspectiva de que a cura pode ser descoberta? Qual instituição controlaria a feitura, aplicação e resultado dos testes? Qual o nível de acesso da população a esse avanço da medicina? Em que fase da vida os testes deveriam ser feitos - pré-

\section{Referências}

1. Casabona CMR. Do gene ao Direito: sobre implicações jurídicas do conhecimento e intervenção do genoma humano. São Paulo: IBCCRIM; 1999. implantação, após-nascimento, infância? Qual seria o comportamento de laboratórios de pesquisa genética na possibilidade de um embate entre interesses comerciais, interesses de pesquisa e o respeito à ética? Quem vai dar a última palavra sobre as questões trazidas pelo aspecto ético desse avanço genético?

Não há um consenso sobre tantos questionamentos, que surgem e se ramificam o tempo todo, comprovando que cada caso merece uma análise individual. Entretanto, nas discussões que têm sido levantadas 4 em relação aos testes preditivos, observa-se, em geral, uma convergência de opinião sobre sua aplicação em crianças assintomáticas para doenças de início tardio apenas quando há possibilidades claras de tratamento precoce visando à cura ou à diminuição dos efeitos da doença. Nesse caso, então, a decisão seria dos pais ou responsáveis. De outra forma, deve-se aguardar para que a criança, tornada adulta, resolva por si mesma. Também há um consenso quanto à necessidade de uma concordância expressa para a realização dos testes, não se admitindo que amostras sejam retiradas ou testadas 10 sem a anuência de seu proprietário e sem que esse saiba quais genes serão analisados.

\section{Considerações finais}

Cada um dos aspectos aqui questionados conduz a inúmeros outros, dentro de inúmeros campos do saber e sob inúmeras perspectivas, mas, em maior ou menor profundidade, pode-se detectar uma constante permeando o conjunto de interrogações: a preocupação com o resguardo de uma ética de vida em paralelo aos avanços tecnocientíficos ofertados pela medicina no campo da genética. Isso significa dizer que uma espécie de "cobrança bioética" tem inspirado (felizmente, a nosso ver) as discussões de casos sobre o diagnóstico prévio de doenças genéticas de início tardio. Acreditamos que, enquanto mantivermos viva a reflexão sobre o assunto, norteada por princípios éticos e de respeito à individualidade de cada caso, será possível se chegar a soluções benéficas em relação aos testes preditivos em doenças de manifestação tardia. De fato, só desse modo se poderá ambicionar uma perspectiva casuística na avaliação de cada caso, garantindo desse modo o respeito inexorável pela dignidade humana.
2. Mustacchi Z, Peres S, organizadores. Genética baseada em evidências: síndromes e heranças. São Paulo: CID Editora; 2000 . 
3. Coutinho APA. Ética na Medicina. Petrópolis: Vozes; 2006.

4. Zatz M. A biologia molecular contribuindo para compreensão e a prevenção das doenças hereditárias. 2002. [acesso em 1 Nov 2010] Disponível em: http://www.scielo.br/scielo.php?script=sci_arttext\&pid=S1 413-81232002000100008\&lng=en.

5. Fachin LE. Discriminação por motivos genéticos In: Sá MFF, Naves BTO, coordenadores. Bioética, Biodireito e o Código Civil de 2002. Belo Horizonte: Del Rey; 2004.

6. Jatene FB, Cutait R, coordenadores. Projeto Diretrizes: testes preditivos. São Paulo: Associação Médica Brasileira e Conselho Federal de Medicina; 2002.

7. Nunes RML. Questões éticas do diagnóstico pré-natal da doença genética [tese doutorado]. Porto: Faculdade de Medicina do Porto; 1995.

Recebido em 5 de abril de 2010

Versão final apresentada em 20 de setembro de 2010

Aprovado em 5 de outubro de 2010
8. Castanha AR, Coutinho MPL, Saldanha AAW, Ribeiro CG. Repercussões psicossociais da depressão no contexto da Aids. Psicol Ciênc Prof. 2006; 26: 70-81. [acesso em 1 Nov 2010]. Disponível em: http://pepsic.bvsalud.org/scielo.php? script=sci arttext\&pid=S1414-98932006000100007\&lng= pt\&nrm=iso [2010 Nov 01]

9. Buiatti M. Biotecnologias: a engenharia genética entre biologia, ética e mercado. São Paulo: Edições Loyola; 2004.

10. Zatz M. Genética e ética. R CEJ Brasília. 2002; 16: 13-28. [2010 Nov 01]. Disponível em: http://www2.cjf.jus.br/ojs2/ index.php/cej/article/viewFile/441/622 